\title{
Specifying the EKC: Downstream Dependence in Water Pollution
}

\author{
Alexi Thompson \\ Department of Economics, Indiana University of Pennsylvania, Indiana, USA \\ Email: Alexi.Thompson@iup.edu
}

Received 26 September 2014; revised 27 October 2014; accepted 14 November 2014

Copyright (C) 2014 by author and Scientific Research Publishing Inc.

This work is licensed under the Creative Commons Attribution International License (CC BY). http://creativecommons.org/licenses/by/4.0/

(c) (7) Open Access

\section{Abstract}

The present study provides a utility maximizing theoretical framework motivating the EKC model. Theoretical parameters are linked directly to the typical empirical parameters of the reduced form empirical EKC model. Linking the theory to the typical empirically estimated parameters is relevant for devising policy and future EKC studies.

\section{Keywords}

\section{Environmental Kuznets Curve, Downstream Dependence, Water Pollution}

\section{Introduction}

The environmental Kuznets curve (EKC) describes the relationship between income per capita and environmental degradation as an inverted $U$-shape. At initial stages of economic development and low income per capita, environmental degradation increases with income because increased production leads to pollution. Eventually, the environmental problems are redressed as demand for environmental quality increases with rising income.

Since the initial EKC study by [1], a number empirical EKC studies have been published [2]-[9]. Theoretical EKC models that have been developed to help motivate the EKC have included infinitely-lived agent models ([10] [11]) and overlapping generation models ([12]). [13] develop the Green Solow Model, an extension of the Solow model including a resource constraint.

[14] approach the EKC from a consumer standpoint and assumes increasing returns to pollution abatement. These authors derive conditions for a turning point or the point at which pollution degradation is maximized. The present study provides a utility maximizing theoretical framework motivating the EKC model. Theoretical parameters are linked directly to the typical empirical parameters of the reduced form empirical EKC model. Linking theoretical parameters to the typical empirically estimated parameters is relevant for devising policy and future EKC studies. 


\section{Theory}

Consider agent 1 in the upstream country $(U)$ and agent 2 in the downstream country $(D)$. The utility of agent 1 is a general function of their consumption and pollution,

$$
U_{U}=U\left(C_{U}, P_{U}\right)
$$

and the downstream agent utility is a function of their consumption and pollution,

$$
U_{D}=U\left(C_{D}, P_{D}\right)
$$

Utility is quasi-concave in $C$ and $P$ for upstream and downstream agents. Pollution in the upstream country is a function of consumption $C_{U}$ and environmental effort $E_{U}$,

$$
P_{U}=P_{U}\left(C_{U}, E_{U}\right)
$$

where $\left(\frac{\delta P_{U}}{\delta C_{U}}\right)>0$ and $\left(\frac{\delta P_{U}}{\delta E_{U}}\right)<0$.

Pollution in the downstream country is a function of consumption and environmental effort in the downstream country, plus the fraction of upstream pollution that travels downstream,

$$
P_{D}=P_{D}\left(C_{D}, E_{D}\right)+\lambda P_{U}
$$

where $\left(\frac{\delta P_{D}}{\delta C_{D}}\right)>0$ and $\left(\frac{\delta P_{D}}{\delta E_{D}}\right)<0$.

Income $Y$ is spent on consumption $C$ and environmental effort $E$ Prices of $C$ and $E$ are normalized to 1 in the income constraint

$$
Y_{i}=C_{i}+E_{i}
$$

where $i=U, D$.

In a specified utility function, agent $i$ maximizes

$$
U_{i}=C_{i}-z_{i} P_{i}
$$

where $z_{i}$ is the constant marginal disutility of pollution assumed equal to one. Upstream utility

$$
U_{U}=\delta_{0} C_{U}-\delta_{1} C_{U}^{2}-z_{U} P_{U}
$$

where $z_{U}$ is the marginal disutility of pollution assumed equal to one. Upstream pollution is a quadratic function of consumption and environmental effort in upstream and downstream countries,

$$
P_{U}=\gamma_{0} C_{U}-\gamma_{1} C_{U}^{2}-E_{U}+\alpha_{2} E_{U}^{2}
$$

Substituting the pollution function into the utility function utility $U_{U}=\left(\delta_{0}-\gamma_{0}\right) C_{U}-\left(\delta_{1}-\gamma_{1}\right) C_{U}^{2}+E_{U}-\alpha_{2} E_{U}^{2}$. For notational convenience let $\left(\delta_{0}-\gamma_{0}\right)=\alpha_{0}$ and $\left(\delta_{1}-\gamma_{1}\right)=\alpha_{1}$. To ensure that the reduced form utility function is concave, assume $\alpha_{0}>0$ and $\alpha_{1}>0$ which in turn require the parameter restrictions $\delta_{0}>\gamma_{0}$ and $\delta_{1}>\gamma_{1}$.

The upstream agent chooses consumption and effort to maximize utility, subject to the budget constraint $Y_{U}=C_{U}+E_{U}$. The adding-up conditions on the solutions to this problem require the further parameter restriction that $\alpha_{0}=1^{1}$. Optimal consumption and effort levels in the upstream country are

$$
C_{U}^{*}=\left(\frac{\alpha_{2} Y_{U}}{\alpha_{1}+\alpha_{2}}\right)
$$

\footnotetext{
${ }^{1}$ To see this, note that the solutions to the problem are of the form $c_{U}^{*}=\left(\frac{\alpha_{0}-1+2 \alpha_{2} Y_{U}}{2\left(\alpha_{1}+\alpha_{2}\right)}\right)$ and $E_{U}^{*}=\left(\frac{1-\alpha_{0}+2 \alpha_{1} Y_{U}}{2\left(\alpha_{1}+\alpha_{2}\right)}\right)$. To fulfill the budget constraint that $c_{U}^{*}+E_{U}^{*}=Y_{U}$ for all $Y_{U}>0$ we must have $\alpha_{0}=1$.
} 


$$
E_{U}^{*}=\left(\frac{\alpha_{1} Y_{U}}{\alpha_{1}+\alpha_{2}}\right)
$$

In general $U_{D}=f\left(C_{D}, P_{D}\right)$ or

$$
U_{D}=\delta_{2} C_{D}-\delta_{3} C_{D}^{2}-z_{D} P_{D}
$$

Again $z_{D}$ represents marginal disutility of pollution in the downstream country, assumed equal to one.

Pollution in the downstream country is

$$
P_{D}=\gamma_{2} C_{D}-\gamma_{3} C_{D}^{2}-E_{D}+\alpha_{4} E_{D}^{2}+\lambda P_{U}^{*}
$$

where $\lambda$ represents the fraction of upstream pollution that flows downstream. For simplicity, assume $\lambda=1$ so that all upstream pollution flows downstream. Substituting (8) into (12) expresses downstream pollution as a function of upstream and downstream consumption and environmental effort,

$$
P_{D}=\gamma_{0} C_{U}^{*}-\gamma_{1} C_{U}^{* 2}-E_{U}^{*}+\alpha_{2} E_{U}^{* 2}+\gamma_{2} C_{D}-\gamma_{3}\left(C_{D}\right)^{2}-E_{U}+\alpha_{2}\left(E_{U}^{2}\right)^{*}
$$

The potential of diminishing returns to pollution with respect to consumption and environmental effort is preserved from the A\&L model.

Substituting (13) into (11) the utility of the downstream citizen is a function of their own consumption and environmental effort as well as upstream consumption and environmental effort,

$$
U_{D}=\left(\delta_{0}-\gamma_{0}\right) C_{U}^{*}-\left(\delta_{1}-\gamma_{1}\right) C_{U}^{* 2}+E_{U}-\alpha_{2} E_{U}^{2}+\left(\delta_{2}-\gamma_{2}\right) C_{D}-\left(\delta_{3}-\gamma_{3}\right) C_{D}^{2}+E_{D}-\alpha_{4} E_{D}^{2}
$$

subject to the constraint on income, $Y_{D}=C_{D}+E_{D}$. As above, impose the parameter restrictions $\left(\delta_{0}-\gamma_{0}\right)=1$, $\left(\delta_{2}-\gamma_{2}\right)=1$, and let $\left(\delta_{1}-\gamma_{1}\right)=\alpha_{1}$ and $\left(\delta_{3}-\gamma_{3}\right)=\alpha_{3}$.

Treating $C_{U}^{*}$ and $E_{U}^{*}$ as constants and solving for optimal consumption and environmental effort in the downstream country yields

$$
\begin{aligned}
& C_{D}^{*}=\left(\frac{\left(\alpha_{4}\right)}{\alpha_{3}+\alpha_{4}}\right) Y_{D} \\
& E_{D}^{*}=\left(\frac{\alpha_{3}}{\alpha_{3}+\alpha_{4}}\right) Y_{D}
\end{aligned}
$$

Substituting (9), (10), (15), and (16) in the downstream pollution function

$$
P_{D}=\gamma_{0} C_{U}^{*}-\gamma_{1}\left(C_{U}^{*}\right)^{2}-E_{U}^{*}+\alpha_{2}\left(E_{U}^{*}\right)^{2}+\gamma_{2} C_{D}^{*}-\gamma_{3}\left(C_{D}^{*}\right)^{2}-E_{D}^{*}+\alpha_{4}\left(E_{D}^{*}\right)^{2}
$$

and combining like terms and simplifying yields

$$
P_{D}=\left(\frac{\left(\alpha_{2}-\alpha_{1}\right)}{\alpha_{1}+\alpha_{2}}\right) Y_{U}+\left(\frac{\alpha_{2} \alpha_{1}^{2}-\gamma_{1} \alpha_{2}^{2}}{\left(\alpha_{1}+\alpha_{2}\right)^{2}}\right) Y_{U}^{2}+\left(\frac{\left(\alpha_{4}-\alpha_{3}\right)}{\alpha_{3}+\alpha_{4}}\right) Y_{D}+\left(\frac{\alpha_{4} \alpha_{3}^{2}-\gamma_{3} \alpha_{4}^{2}}{\left(\alpha_{3}+\alpha_{4}\right)^{2}}\right) Y_{D}^{2}
$$

Equation (18) requires the further restriction $\gamma_{0}=1$ and $\gamma_{2}=1$.

The estimated EKC model follows

$$
P_{D}=\beta_{0}+\beta_{1} Y_{U}+\beta_{2} Y_{U}^{2}+\beta_{3} Y_{D}+\beta_{4} Y_{D}^{2}
$$

where $P_{D}$ is BOD per capita, $Y_{U}$ is upstream income, $Y_{D}$ is downstream income, and $\beta^{\prime}$ s are coefficients to be estimated.

Linking the theoretical model with the empirical model, the second order marginal effects of consumption and effort on utility for the upstream country $\alpha_{1}$ and $\alpha_{2}$ and downstream country $\alpha_{3}$ and $\alpha_{4}$ can be derived from the following:

$$
\left(\frac{\left(\alpha_{2}-\alpha_{1}\right)}{\alpha_{1}+\alpha_{2}}\right)=\beta_{1}
$$




$$
\begin{aligned}
& \left(\frac{\alpha_{2} \alpha_{1}^{2}-\gamma_{1} \alpha_{2}^{2}}{\left(\alpha_{1}+\alpha_{2}\right)^{2}}\right)=\beta_{2} \\
& \left(\frac{\left(\alpha_{4}-\alpha_{3}\right)}{\alpha_{3}+\alpha_{4}}\right)=\beta_{3} \\
& \left(\frac{\alpha_{4} \alpha_{3}^{2}-\gamma_{3} \alpha_{4}^{2}}{\left(\alpha_{3}+\alpha_{4}\right)^{2}}\right)=\beta_{4}
\end{aligned}
$$

Solving for $\alpha_{3}$ in terms of $\beta_{3}, \beta_{4}$, and $\gamma_{3}$ yields

$$
\alpha_{3}=\left(\frac{4 \beta_{4}+\gamma_{3}\left(1+\beta_{3}\right)^{2}}{\left(1-\beta_{3}\right)^{2}}\right)
$$

The parameter $\gamma_{3}$ is unknown. The parameter $\gamma_{3}$ can take any positive value as long as $\left(\frac{\delta U_{D}}{\delta C_{D}}\right)>0$. Let $\gamma_{3}=0.5$. Once $\alpha_{3}$ is solved, the following expression can solve for $\alpha_{4}$ :

$$
\alpha_{4}=\left(\frac{\alpha_{3}\left(1+\beta_{3}\right)}{1-\beta_{3}}\right) .
$$

The parameters $\alpha_{1}$ and $\alpha_{2}$ can be solved using $\beta_{1}$ and $\beta_{2}$ in a similar manner.

Although this model is somewhat restrictive, this appears to be the first attempt to link a theoretical model of an EKC with an empirical model. This is important because the underlying causes of an EKC are debated. Some EKC theorists believe citizens make "greener" consumption choices as they grow richer, while other theorists believe the EKC is a reflection of harsher environmental regulations in higher income countries. The EKC empirical estimates can derive underlying second order effects of consumption and effort on utility. Results may offer insight into how consumers value consumption and effort and where their income should be spent.

\section{Conclusion}

This paper investigates downstream dependence in an EKC for water pollution. The question this paper addresses is whether downstream pollution can be redressed with income growth in the upstream country. A theoretical model is developed that relates theoretical parameters directly with the typical empirically estimated parameters of the reduced form EKC model. Theoretical parameters for upstream and downstream county consumption and environmental effort are derived. Future EKC studies may benefit from employing the theoretical model proposed in this paper to help devise appropriate policy for various pollution indicators.

\section{Acknowledgements}

Special thanks to Jeff Peterson, John Crespi, and Henry Thompson for comments.

\section{References}

[1] Grossman, G.M. and Krueger, A.B. (1991) Environmental Impacts of a North American Free Trade Agreement. NBER Working Paper 3914.

[2] Perman, R. and Stern, D.I. (2003) Evidence from Panel Unit Root and Cointegration Tests That the Environmental Kuznets Curve Does Not Exist. Australian Journal of Agricultural and Resource Economics, 47, 325-347.

[3] Panayotou, T. (1993) Empirical Tests and Policy Analysis of Environmental Degradation at Different Stages of Economic Development. Working Paper WP238, Technology and Employment Programme, International Labour Office, Geneva.

[4] Panayotou, T. (1995) Environmental Degradation at Different Stages of Economic Development. In: Ahmed, I. and Doeleman, J.A., Eds., Beyond Rio: The Environmental Crisis and Sustainable Livelihoods in the Third World, ILO Studies Series, St. Martin’s Press, New York. 
[5] Sigman, H. (2002) International Spillovers and Water Quality in Rivers: Do Countries Free Ride? American Economic Review, 92, 1152-1159. http://dx.doi.org/10.1257/00028280260344687

[6] Helland, E. and Whitford, A.B. (2003) Pollution Incidence and Political Jurisdiction: Evidence from the TRI. Journal of Environmental Economics and Management, 46, 403-424. http://dx.doi.org/10.1016/S0095-0696(03)00033-0

[7] Maddison, D. (2006) Environmental Kuznets Curves: A Spatial Econometric Approach. Journal of Environment and Economics Resources, 51, 218-230.

[8] Paudel, K.P., Zapata, H. and Susanto, D. (2005) An Empirical Test of Environmental Kuznets Curve for Water Pollution. Environmental and Resource Economics, 31, 325-348. http://dx.doi.org/10.1007/s10640-005-1544-5

[9] Barua, A. and Hubacek, K. (2009) An Empirical Analysis of the Environmental Kuznets Curve for Water Pollution in India. International Journal of Global Environmental Issues, 9, 50-68. http://dx.doi.org/10.1504/IJGENVI.2009.022084

[10] Lopez, R. (1994) The Environment as a Factor of Production: The Effects of Economic Growth and Trade Liberalization. Journal of Environmental Economics and Management, 27, 163-184. http://dx.doi.org/10.1006/jeem.1994.1032

[11] Selden, T.M. and Song, D. (1994) Environmental Quality and Development: Is There an Environmental Kuznet's Curve for Air Pollution? Journal of Environmental Economics and Management, 27, 147-162. http://dx.doi.org/10.1006/jeem.1994.1031

[12] John, A. and Pecchenino, R. (1994) An Overlapping Generation Model of Growth and the Environment. Economic Journal, 104, 1393-1410. http://dx.doi.org/10.2307/2235455

[13] Brock, W.A. and Taylor, M.S. (2010) The Green Solow Model. Journal of Economic Growth, 15, 127-153. http://dx.doi.org/10.1007/s10887-010-9051-0

[14] Andreoni, J. and Levinson, A. (2001) The Simple Analytics of the Environmental Kuznets Curve. Journal of Public Economics, 80, 269-286. http://dx.doi.org/10.1016/S0047-2727(00)00110-9 
Scientific Research Publishing (SCIRP) is one of the largest Open Access journal publishers. It is currently publishing more than 200 open access, online, peer-reviewed journals covering a wide range of academic disciplines. SCIRP serves the worldwide academic communities and contributes to the progress and application of science with its publication.

Other selected journals from SCIRP are listed as below. Submit your manuscript to us via either submit@scirp.org or Online Submission Portal.
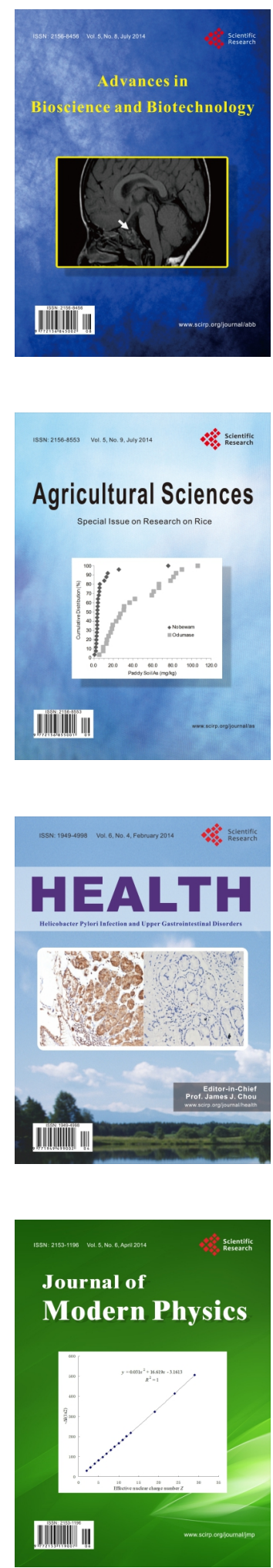
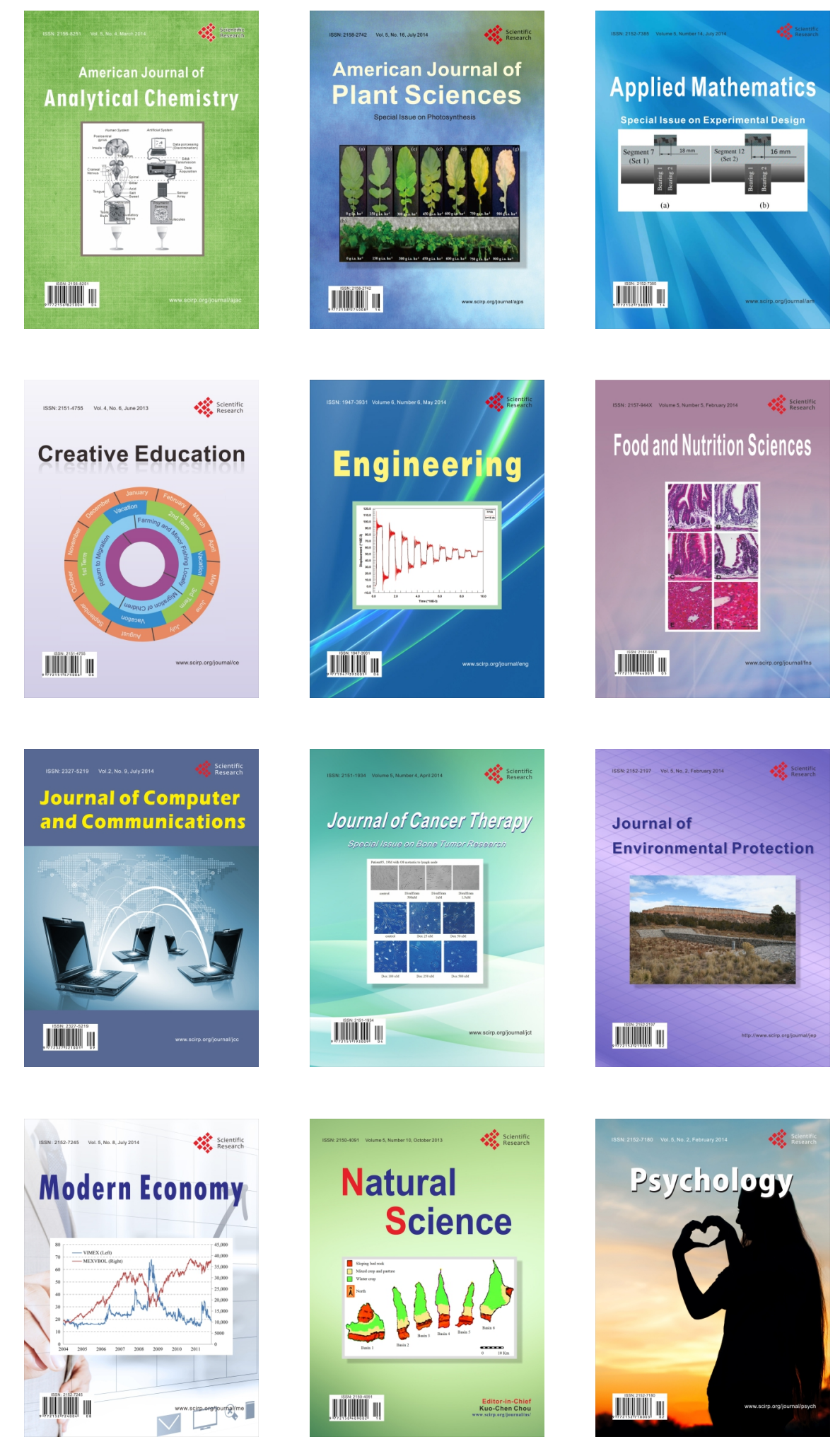